\title{
ARTICLE
}

\section{Basic counselling skills}

\author{
T Brand, BSocSci (SW), MSW (Clinical Practice) \\ Umduduzi Hospice Care for Children, Durban, South Africa
}

Corresponding author: T Brand (tracey@umduduzi.co.za)

George Bernard Shaw stated, 'The single biggest problem in communication is the illusion that it has taken place'. In the medical world, and especially one that involves children, this is unfortunately a reality.

S Afr Med J 2014;104(7):511. DOI:10.7196/SAMJ.8434

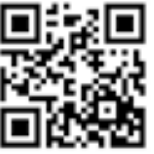

We all communicate. Whenever we are in contact with other people, we send and receive messages. Because we all communicate, we tend to take communication for granted and assume that our natural communication abilities are adequate.

Children have a right to participate in decision making regarding their healthcare and parents/caregivers have a right to be told the whole truth. Not talking about something does not mean that we are not communicating. Avoidance is a message in itself. But how do we do this?

\section{Breaking bad news}

Breaking bad news is never easy. Good breaking of bad news may enhance a family's coping abilities. Poor breaking of bad news may have a profound effect on a family's functioning and anticipatory grief response.

Buckman $^{[1]}$ highlighted the following six steps that need to be taken when breaking bad news:

Step 1 - Getting started

Step 2 - Finding out how much the patient knows

Step 3 - Finding out how much the patient wants to know

Step 4 - Sharing the information

Step 5 - Responding to the patient's feelings

Step 6 - Planning and follow-through

\section{Step 1 - Getting started}

Buckman $^{[1]}$ describes the importance of the physical context. Introduce yourself. Check where you are sitting with regard to the patient and the family. Is there an appropriate distance between you and the patient and/or the family? This is especially relevant if you are tactile and someone for whom touch is important. You don't want to be at the opposite side of the room when you need to give the patient a comforting pat on the arm or hand.

Body language is also critically important. It is imperative that we are at ease and attentive to all the patient's needs. In this regard the SOLER $^{[2]}$ approach is very helpful:

$\mathbf{S}$ - Sit squarely to the patient

O - Adopt an open posture

L - Lean slightly towards the patient

E - Maintain eye contact if culturally appropriate, except when the patient is expressing anger or crying

R - RELAX.

\section{Step 2 - Finding out how much the patient knows}

It is important that we ascertain how much information the patient already has, whether from us or other sources. To achieve this, one may ask the patient to tell their story from when they first became ill to where they are now. Consequently, the patient or the family often begin to realise the seriousness of the situation. They may then already be prepared for the news that you have to give them.

\section{Step 3 - Finding out how much the patient wants to know} While telling their story, the patient and/or family might mention what they do not fully understand. It is our responsibility to check whether they require more information or further explanation. It is vitally important that we respect both the patient's and the family's views. It is not our responsibility to force information onto them. However, in the same vein, we should not hide information from patients and/or families because of a desire to 'protect' each other.

\section{Step 4 - Sharing the information}

Breaking bad news requires a certain technique. Here we adopt the WPC method, where we break bad news up into a series of chunks:

W - Warn the family and/or patient that there is bad news. This gives them a chance to prepare/brace themselves. Sometimes you will see the family or patient physically brace themselves for the news that you are about to give. 'I would like to talk to you about something that you will probably find difficult.'

$\mathbf{P}$ - Pause until they are ready and then present only one piece (chunk) of information at a time. 'I have some bad news about your diagnosis.'

C - Check back to ensure that they have correctly understood the information and that the news is embedded in the person's memory. 'Shall we discuss that a little before we move on?'

At this stage it is important that the information is given in chunks. 'You have terminal cancer' is more than one piece of bad news. Utilising the WPC method, you could break down the news as follows:

- You have an illness.

- The illness is serious.

- It is serious enough to lead to your death.

- You will probably become quite ill before you die.

- You might be in pain or discomfort, but we can manage it.

- You will have a lot of things to do before you die.

- You might have to think about what comes after death. 
Between each of these above-mentioned sentences you would warn that there is more bad news, pause before giving it, and check back that it has been understood and the family and/or patient is ready for more.

\section{Step 5 - Responding to the patient's feelings}

It is important that we acknowledge what the family and/or patient is feeling and where possible normalise these feelings. One might say, 'I can see that you are angry. That's OK.' Ignoring or minimising their feelings negates their experience and can lead to denial patterns and complicated grief patterns.

After each chunk of bad news, accept the emotion that follows. Do not worsen the situation. Be gentle, kind and reassuring.

Once the response settles, you should repeat the process until one of four things happens:

- There is no more bad news to break.

- They signal that they have heard enough.

- You get the feeling that they have stopped hearing or absorbing.

- You feel that you cannot do anything more (which is fine, as long as you make sure you arrange to return).

\section{Step 6 - Planning and following through}

Once you have given a family and/or patient bad news, they must not feel abandoned. Knowing what the next steps are and what still needs to happen, as well as following through on that, assists them in dealing with the news and further emphasises your conversation with them.

It is important that you begin to identify available options, suggest sources of support and start discussing management plans. Ensure that the family is able to contact you or a colleague within a few days.

Breaking bad news is a very important part of medical care and must not be taken lightly. Before engaging with the family and/or patient, ensure that you have enough time for the conversation, that you have all the information you may need and that there is a suitable area where you can converse.

Confidentiality is also crucial, but not if it will jeopardise teamwork or enforce the conspiracy of silence. It is important that we inform the family and patient that some of their comments/thoughts would need to be shared with the rest of the treating team. In such cases, we need to bring these comments/thoughts to the attention of the family and/ or patient and ask whether they wish to inform the team or whether we should inform them. When working with children, it becomes difficult. We often first speak to the parents, who ask that we do not tell the child what is happening in order to protect the child. It is very important that we inform the family that we will not lie to the child. We will not rush into their room and tell them that they are dying.
However, if the child asks directly what is happening, we will answer their questions honestly.

\section{What not to say}

- Don't talk about youself or compare the situation with something that you have experienced.

- If the patient/family does not want to talk, don't force the issue. Let them know that you are available when and if they want to talk.

- Don't try to find the positives. There isn't much of a silver lining to a diagnosis of blood cancer, so avoid saying, for example, 'It could be worse' or 'At least it isn't .... For the person with the disease, this is probably the worst-case scenario.

- At the same time, don't express an overly pessimistic opinion.

- Don't leave if things get tough. If the person becomes angry, let them vent their anger. If they tell you that they are afraid, open up the conversation so that they can unburden. 'What are you most afraid of?', 'What can I do to help with your fears?'. These situations can be hard to manage, but put them right back in the patient's court and let them do the talking. That way, you don't need to worry about what to say.

- Avoid saying things that minimise what the patient is going through, such as 'Don't worry', 'Everything is going to be OK', or 'Cheer up'.

- Nobody deserves to develop cancer. Even if you believe that the person's lifestyle choices contributed to the disease, or if you think it was 'God's will' that it happened, keep it to yourself.

\section{Conclusion}

Talking to our patients, irrespective of their age, about what is happening to them is a crucial part of who we are. It is therefore imperative that we find a way to communicate effectively. Talking at someone for 45 minutes does not constitute counselling them extensively. Finding a way to communicate effectively by overcoming our fears, and meeting the person where they are, allow for listening and talking to be truly inclusive and contribute to effective communication, understanding and caring in the doctor-patient relationship.

\section{References}

1. Buckman R. How to Break Bad News: A Guide for Health Care Professionals. Baltimore, MD: John Hopkins Press, 1992.

2. Egan G. The Skilled Helper. Pacific Grove, CA: Thomas Brooks/Cole, 1994. 